\title{
Review \\ Tissue engineering in the rheumatic diseases
}

\author{
Jochen Ringe and Michael Sittinger
}

Tissue Engineering Laboratory and Berlin-Brandenburg Center for Regenerative Therapies, Department of Rheumatology and Clinical Immunology, Charité - Universitätsmedizin Berlin, Tucholskystr. 2, 10117 Berlin, Germany

Corresponding author: Jochen Ringe, jochen.ringe@charite.de

Published: 30 January 2009

This article is online at http://arthritis-research.com/content/11/1/211

(c) 2009 BioMed Central Ltd

Arthritis Research \& Therapy 2009, 11:211 (doi:10.1186/ar2572)

\begin{abstract}
Diseases such as degenerative or rheumatoid arthritis are accompanied by joint destruction. Clinically applied tissue engineering technologies like autologous chondrocyte implantation, matrixassisted chondrocyte implantation, or in situ recruitment of bone marrow mesenchymal stem cells target the treatment of traumatic defects or of early osteoarthritis. Inflammatory conditions in the joint hamper the application of tissue engineering during chronic joint diseases. Here, most likely, cartilage formation is impaired and engineered neocartilage will be degraded. Based on the observations that mesenchymal stem cells (a) develop into joint tissues and (b) in vitro and in vivo show immunosuppressive and anti-inflammatory qualities indicating a transplant-protecting activity, these cells are prominent candidates for future tissue engineering approaches for the treatment of rheumatic diseases. Tissue engineering also provides highly organized three-dimensional in vitro culture models of human cells and their extracellular matrix for arthritis research.
\end{abstract}

\section{Introduction}

Diseases like rheumatoid arthritis (RA) or degenerative arthritis (osteoarthritis, OA) are accompanied by a progressive reduction of extracellular matrices (ECMs) in joint cartilage and bone and, eventually, loss of joint function and excessive morbidity. Current pharmacological treatment of RA focuses on alleviating symptoms and/or modifying the disease process. Despite recent success in controlling pain and inflammation, marginal cartilage regeneration has been observed. Obviously, suppression of inflammation is not sufficient to restore joint structure and function. Probably, cartilage repair may be achieved only by triggering local cartilage tissue responses leading to recovery of chondrocyte remodelling. An imbalance in joint cartilage, subchondral bone, and synovial membrane remodelling is one important characteristic of OA. Despite many OA research efforts, treatment strategies are poor and restricted to relieving the symptoms, to different surgical procedures (including tech- niques stimulating self-repair of the joint) $[1,2]$, or to endoprothetic joint replacement.

In the last decade, tissue engineering approaches for the repair of joint cartilage and bone defects have reached the clinic. Here, autologous cells are transplanted as cell suspension or in combination with supportive scaffolds into the defect site or, since 2007, are in situ recruited to the defect site due to the implantation of scaffolds combined with cell attractants. Meanwhile, the scope of clinical application for tissue engineering was expanded to OA diseased joint cartilage $[3,4]$.

Besides clinically applied tissue-specific chondrocytes, undifferentiated mesenchymal stem cells (MSCs) are of special interest as cell candidates. In particular, bone marrow MSCs are comprehensively characterized and represent promising candidates [5]. They are easy to isolate and expand, they differentiate into various tissues like cartilage [6] and bone [7], and therefore they are able to regenerate osteochondral defects. Additionally, as they target diseased organs and secrete many bioactive factors, such as immunosuppressives for $\mathrm{T}$ cells facilitating their allogeneic use, they serve as vehicles capable of presenting proteins with therapeutic effects. In this regard, secreted bioactive factors provide a regenerative environment, referred to as trophic activity, stimulating, for instance, mitosis and differentiation of tissueintrinsic repair or stem cells (reviewed in [8]). Because of their anti-inflammatory and immunosuppressive properties, MSCs have been used as agents in autoimmune diseases (ADs) and have been applied in arthritis animal models (reviewed in [9]). The applicability of further cell types, such as joint-inherent cells, embryonic stem cells (ESCs), or recently described induced pluripotent stem cells (iPSs), is under vigorous investigation.

$3 \mathrm{D}=$ three-dimensional; $\mathrm{ACl}=$ autologous chondrocyte implantation; $\mathrm{AD}=$ autoimmune disease; $\mathrm{ECM}=$ extracellular matrix; $\mathrm{ESC}=$ embryonic stem cell; GvHD = graft versus host disease; $\mathrm{HA}=$ hyaluronic acid; HSCT = hematopoietic stem cell transplantation; IL = interleukin; iPS $=$ induced pluripotent stem cell; $\mathrm{MACl}=$ matrix-assisted autologous chondrocyte implantation; $\mathrm{MHC}$ = major histocompatibility complex; $\mathrm{MSC}=$ mesenchymal stem cell; OA = osteoarthritis; PLGA = poly(DL-lactic acid-co-glycolic acid); RA = rheumatoid arthritis; RASF = rheumatoid arthritis synovial fibroblast; TGF- $\beta 3=$ transforming growth factor-beta-3; TNF- $\alpha=$ tumor necrosis factor-alpha. 
Another important tissue engineering branch focuses on three-dimensional (3D) in vitro models. Here, highly organized $3 \mathrm{D}$ in vitro cultures of cells and their ECMs reflect the human situation under well-defined and reproducible conditions. Recently, 3D in vitro models to study destructive pathophysiological processes leading to cartilage breakdown in $\mathrm{OA}$ and RA $[10,11]$ and for high-throughput screening of antirheumatic drugs have been established [12].

\section{Joint tissue engineering: clinical applications}

The first entry for the key word 'tissue engineering', also termed 'regenerative medicine', in the National Center for Biotechnology Information database PubMed was in 1984 (Figure 1a). Ten years later, in 1994, about 20 entries were added, and in 1999, the first year of publication of Arthritis Research \& Therapy, 250 were added. In 2008, more than 2,700 manuscripts with 'tissue engineering' in the title or abstract were added to PubMed, indicating how dynamic this rapidly emerging field is. Furthermore, about 700 entries for the key word 'regenerative medicine' can be found. Since the first two PubMed entries for 'cartilage' and 'bone tissue engineering' were published in 1991 (accounting for 22\% of all 'tissue engineering' and 'regenerative medicine' entries), values vary between roughly $15 \%$ and $30 \%$ (Figure $1 \mathrm{~b}$ ). Strikingly, although immunologically mediated rheumatic diseases and degenerative joint diseases cause a severe economic burden, the number of PubMed entries for 'tissue engineering' and 'regenerative medicine' and 'arthritis' (36 entries in 2007, which accounted for $1 \%$ of all 'tissue engineering' and 'regenerative medicine' entries) or 'osteoarthritis' (30 entries in 2007 or $0.9 \%$ ) is very low (Figure 1b) and in recent years has not increased to a degree worth mentioning. This may be due to a lack of knowledge of the characteristics of cells from patients with such diseases and possibly due to the destruction of newly engineered tissue in the inflammatory environment.

\section{Autologous chondrocyte implantation for the repair of local cartilage defects}

Joint cartilage is a complex structure consisting of chondrocytes and cartilage-specific ECMs. Today, for cell-based repair, autologous chondrocytes are harvested from unaffected cartilage biopsies, culture-expanded, and injected as a cell suspension or in combination with biomaterials. Autologous chondrocyte implantation (ACl) into human cartilage defects, covered by a periosteal flap to prevent chondrocyte leakage, was described in 1994 [13]. Currently, more than $12,000 \mathrm{ACls}$ are documented. Different studies showed a permanence of clinical results that were gained in a period of about 10 years [14-16]. Despite good clinical results, some disadvantages hamper the prevalence of $\mathrm{ACl}$ : (a) the nonuniform spatial distribution of chondrocytes and the lack of initial mechanical stability, (b) the suture of the periosteal flap into the surrounding healthy cartilage and the necessity of a perifocal solid cartilage shoulder that limits $\mathrm{ACl}$ to the treatment of small defects and excludes the treatment of OA diseased cartilage, and (c) the arthrotomic surgery. Today, collagen sheets have been introduced as one alternative for periosteal flaps [17]. Finally, it should be mentioned that $\mathrm{ACl}$ treatment is still controversial. In a prospective randomized controlled trial (level of evidence: therapeutic level I), no significant advantage for the complex $\mathrm{ACl}$ compared with standard self-repair-stimulating microfracture could be measured after 2 and 5 years [18]. In contrast, also in a prospective randomized controlled trial (level of evidence: therapeutic level I), Saris and colleagues [19] found that $\mathrm{ACl}$ results in better structural repair than microfracture alone when treating symptomatic cartilage defects of the knee.

\section{Matrix-assisted autologous chondrocyte implantation}

Several $\mathrm{ACl}$ drawbacks are avoided in advanced matrixassisted autologous chondrocyte implantation (MACl). Here, 3D constructs of chondrocytes and a carrier scaffold are transplanted into a defect site. Biomaterials are crucial for the temporary stability of transplants, simplify surgical handling, and, just as important, serve as templates for spatial cell growth. Chondrocytes ensure the formation of cartilage tissue through ECM synthesis and are therefore responsible for the long-term stability. Different resorbable transplants based on chondrocytes and collagen [20], hyaluronic acid $[3,21]$, or poly(DL-lactic acid-co-glycolic acid) (PLGA) polymers $[4,22]$ have already reached the clinic. Their fixation depends on the biomechanical properties of the implant and defect localization/size and is ensured by adhesion forces, fibrin glue, or transosseous fixation [23]. In particular, polymers like PLGA allow stable fixation in vast defects, without requiring a perifocal solid cartilage shoulder, one of the major drawbacks of $\mathrm{ACl}$ [22]. Thus, they can be directly fixed onto subchondral bone and have the potential for the repair of OA or arthritic diseased joints. Depending on the material, stable matrices allow the arthroscopic implantation of chondrocytes. In contrast, arthrotomic surgery during $\mathrm{ACl}$ causes approximately $25 \%$ of its specific side effects like fibroarthrosis [14], scar formation, postoperative pain, and limited mobility.

Clinical results of $\mathrm{MACl}$ for up to 5 years are very promising and are comparable to $\mathrm{ACl}[3,4,20,21,24]$. Bartlett and colleagues [24] have performed a prospective randomized comparison of $\mathrm{ACl}$ (collagen type I/type III sheet covered) and $\mathrm{MACl}$ (collagen transplant) for the treatment of symptomatic chondral defects of the knee in 91 patients, of whom 44 were treated with $\mathrm{ACl}$ and 47 with $\mathrm{MACl}$ [24]. Based on an increased modified Cincinnati knee score $(\mathrm{ACl}=17.6$ and $\mathrm{MACl}=19.6)$, good to excellent International Cartilage Repair Society score in $79.2 \%$ of patients treated by $\mathrm{ACl}$ and $66.6 \%$ treated by $\mathrm{MACl}$, hyaline-like cartilage formation $(\mathrm{ACl}=43.9 \%$ and $\mathrm{MACl}=36.4 \%$ ), rate of hypertrophy of the grafts ( $9 \%$ in the $\mathrm{ACl}$ group and $6 \%$ in the $\mathrm{MACl}$ group), and frequency of reoperation ( $9 \%$ in both groups), the authors concluded that after 1 year the clinical, arthroscopic, and histological outcomes are similar for both $\mathrm{ACl}$ and MACl. Marcacci and 

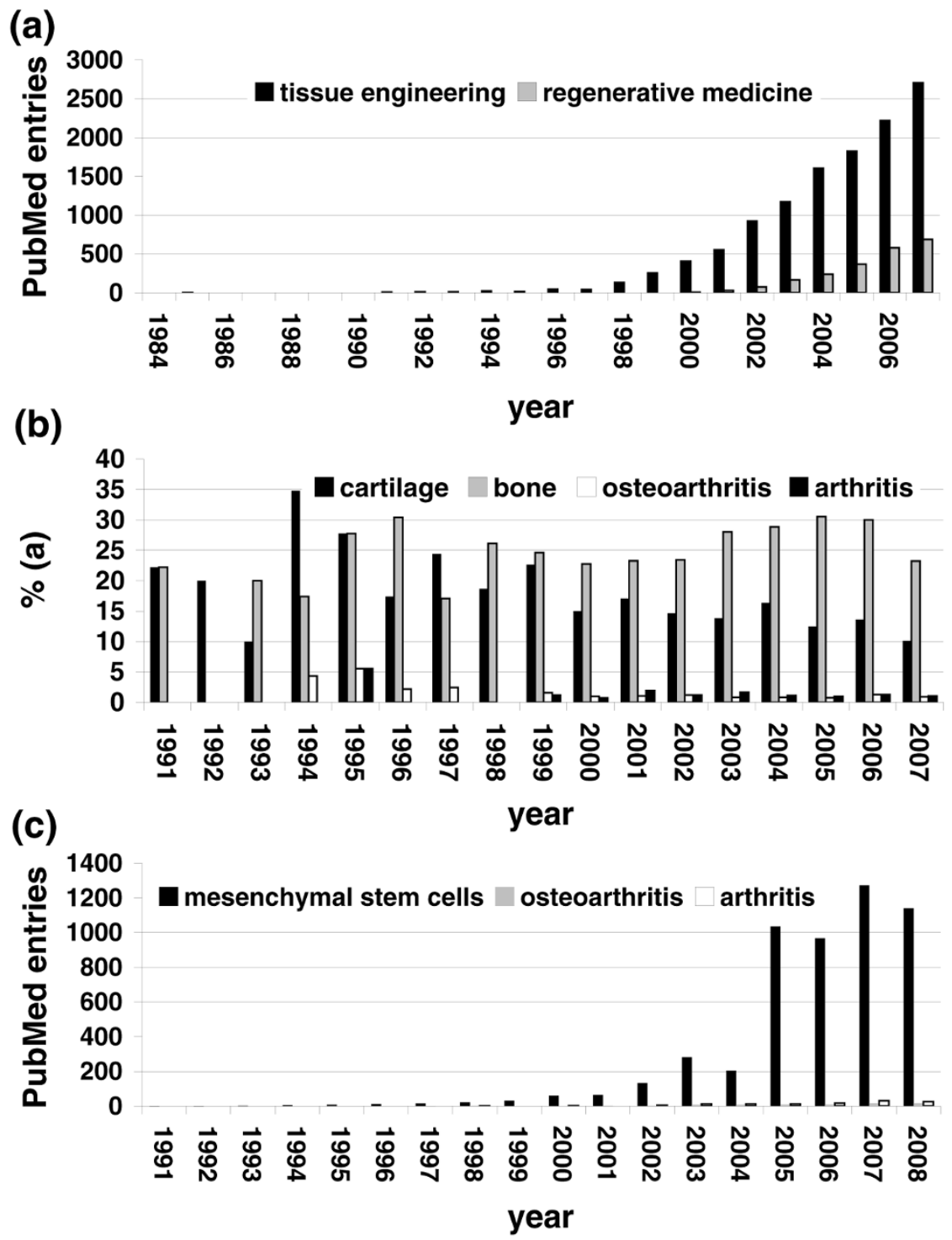

PubMed entries for tissue engineering in the rheumatic diseases. (a) The first entry for the key word 'tissue engineering', also called 'regenerative medicine', in the National Center for Biotechnology database PubMed was in 1984. In 1994, 23 manuscripts were added, and 10 years later, 1,605 were added. In 2008, 2,706 entries for 'tissue engineering' and 688 for 'regenerative medicine' were introduced into PubMed. (b) The first two entries for both 'cartilage' and 'tissue engineering' or 'bone' and 'tissue engineering' were in 1991, accounting for 22\% of all 'tissue engineering' and 'regenerative medicine' entries. Since that year, both values varied between approximately $15 \%$ and $30 \%$. Surprisingly, the number of PubMed entries for 'tissue engineering' or 'regenerative medicine' and 'arthritis' (36 entries in 2007, which accounted for 1\% of all 'tissue engineering' and 'regenerative medicine' entries) or 'osteoarthritis' (30 entries in 2007 or 0.9\%) is very low and in recent years has not increased to a degree worth mentioning. (c) The number of entries for the key word 'mesenchymal stem cells' has also increased dramatically from 1 in 1991 to 1,140 in the first 7 months of 2008 . From these 1,140 entries, only 25 were for 'arthritis' and 'mesenchymal stem cells' and 18 were for 'osteoarthritis' and 'mesenchymal stem cells'.

colleagues [21] presented clinical results for patients with cartilage lesions of the knee who had been treated in a multicenter study (level of evidence: therapeutic study, level III2; retrospective cohort study) with autologous chondrocytes seeded on hyaluronan-based (HYAFF 11) scaffolds. Clinical results of 141 patients with follow-up assessments ranging from 2 to 5 years (average of 38 months) are reported. At follow-up, $92 \%$ of patients improved according to the International Knee Documentation Committee subjective score, $76 \%$ of patients had no pain, and $88 \%$ had no mobility problems. Furthermore, $96 \%$ of the patients had their treated knee in normal or nearly normal condition as assessed by the 
surgeon, cartilage repair was graded arthroscopically as normal or nearly normal in $96.4 \%$ of the scored knees, and the majority of performed second-look biopsies of the grafted site were assessed histologically as hyaline-like cartilage. A very limited complication rate was recorded. More interestingly for patients with degenerative arthritis, $\mathrm{MACl}$ was used in $\mathrm{OA}$ patients. Hollander and colleagues [3] reported the maturation of tissue-engineered cartilage implanted in injured and $\mathrm{OA}$ human knees. In more detail, they analyzed the influence of pre-existing $\mathrm{OA}$ on the regeneration process of knee injury patients after treatment with hyaluronan-based (HYAFF 11) scaffolds. Twenty-three patients, among them 9 with OA, with defect areas of 1.5 to $11.25 \mathrm{~cm}^{2}$ were treated with $\mathrm{MACl}$. A second-look biopsy was taken from each patient after 6 to 30 months (average of 16 months). Standard histological analysis and biochemical analyses involving digestion with trypsin and specific quantitative assays for collagen type I/type II, proteoglycan, and mature and immature collagen crosslinks were performed. In 10 out of 23 patients, hyaline cartilage regeneration was observed after 11 months. In another 10 patients, fibrocartilage was found, and in the remaining patients, three mixed tissues were found. Tissue regeneration was found even when implants were placed in joints that had already progressed to OA. The authors concluded that cartilage injuries can be repaired using tissue engineering and that OA does not inhibit the regeneration process. Furthermore, Ossendorf and colleagues [4] reported the transplantation of autologous chondrocytes embedded in fibrinogen PLGA. The aim of the ongoing prospective observational case report study was to evaluate the efficacy of such transplants for the treatment of post-traumatic and degenerative cartilage defects. Clinical outcome was assessed in 40 patients with a 2-year clinical follow-up prior to implantation and up to 24 months after implantation on the basis of the modified Cincinnati knee score, Lysholm score, Knee Injury and Osteoarthritis Outcome score, and histological analysis of biopsies. Significant improvement of the evaluated scores was observed after 1 and/or 2 years, and histological staining showed integration of the transplants and formation of hyaline cartilage. The Knee Injury and Osteoarthritis Outcome score showed significant improvement in the subclasses of pain, other symptoms, and knee-related quality of life 2 years after treatment in focal $\mathrm{OA}$ defects. The results suggest that $\mathrm{MACl}$ could be a treatment option for the regeneration of $\mathrm{OA}$ defects of the knee.

However, long-term trials of patients with progressed OA are still lacking. Some studies revealed an increased expression of the hypertrophic marker collagen type $X$ and of the dedifferentiation markers collagen type I and type III in chondrocytes from OA patients, whereas the expression of cartilage ECM markers like aggrecan was decreased $[25,26]$. One major question is whether $\mathrm{OA}$ chondrocytes are irreversibly altered. Based on cellular and molecular data, we found that human chondrocytes can be expanded and redifferentiated independently of OA etiology [27].
Although most of the objective and subjective $\mathrm{MACl}$ outcome data, such as the formation of a hyaline-like cartilage matrix and reduction of pain and mobility problems, were positive, current tissue engineering applications clearly do not result in true native tissues. As indicated, for instance, in the study by Hollander and colleagues [3], besides hyaline cartilage, fibrocartilage sometimes is formed. Probably the most important point to improve tissue quality will be the application of advanced transplants. It is known that the ECM milieu surrounding the cells has physical and structural features in the nanometer scale and that this arrangement effects parameters like cell morphology, adhesion, and cytoskeletal organization [28]. Therefore, first materials with nanometer scale structures to simulate the matrix environment were produced and transplanted and, hopefully, will improve neo-tissue quality in the future (reviewed in [29]). Furthermore, the addition of bioactive factors like ECM components or growth and differentiation factors to the advanced scaffolds has the potential to induce, support, or enhance growth and differentiation of cell types toward joint tissues and to orchestrate tissue repair effectively (reviewed in [30]).

\section{Mesenchymal stem cells for joint tissue engineering}

As with the key word 'tissue engineering', the number of PubMed entries for the key word 'mesenchymal stem cells' has increased dramatically (Figure 1c). Since Caplan published his paper 'Mesenchymal stem cells' in 1991 [31], more than 5,200 manuscripts have been added. Starting from 135 publications in 2000, the number increased to 733 in 2005 and to approximately 1,100 during the first 7 months of 2008 .

\section{Preclinical and clinical applications of mesenchymal stem cells}

MSCs derived from various tissues have been preclinically tested for their ability to substitute chondrocytes (reviewed in [32]). Bone marrow MSCs suppress T-cell activity and therefore avoid allogeneic rejection, and because of their plasticity, they are able to form new joint tissues and secrete bioactive factors providing a regenerative environment (trophic activity) that stimulates tissue-intrinsic repair cells or stem cells (reviewed in [8]).

Conflicting data about whether functionally normal MSCs can be isolated from patients with advanced OA have been published. Murphy and colleagues [33] reported that cells from such patients show a decreased proliferative and chondrogenic capacity but that their osteogenic potential is unchanged. In contrast, Scharstuhl and colleagues [34] showed that the chondrogenic potential of human MSCs is independent of age or OA etiology. Similarly, Kafienah and colleagues [35] have studied whether it is possible to engineer hyaline cartilage using bone marrow MSCs derived from patients with hip OA. MSCs were seeded onto polyglycolic acid scaffolds and were chondrogenically stimulated 
using transforming growth factor-beta-3 (TGF- $\beta 3$ ). Based on mRNA, histological, and biochemical analyses of the constructs, transplants showed extensive synthesis of cartilage proteoglycans and collagen type II. Expression of the dedifferentiation marker collagen type I was low. The authors found a protein content almost identical to that of cartilage engineered from bovine nasal chondrocytes and concluded that hyaline cartilage can be engineered using MSCs from $\mathrm{OA}$ patients. We also found no negative effects and have used MSCs from OA joints for in vitro cartilage tissue engineering (Figure 2). MSCs were isolated, expanded in human serum, combined with fibrinogen PLGA (Figure 2a), and TGF- $\beta 3$-induced. At day 28, cell viability was high (Figure 2b) and proteoglycans and cartilage-specific collagen type II were secreted (Figure 2c,e). However, all transplants were also positive for the dedifferentiation marker collagen type I (Figure 2d), suggesting that the newly formed tissue had both hyaline and fibrocartilage contents. We found very similar results for all five OA MSC donors tested. Chondrogenesis was also shown on the mRNA level using genome-wide microarrays. In $\mathrm{OA}$ cultures, we identified crucial elements of the respective molecular machinery of chondrogenesis known from healthy donors [36].

In a goat OA model, OA was induced unilaterally in the knee joint by complete excision of the medial meniscus and resection of the anterior cruciate ligament and then treated by intra-articular injection of MSC/hyaluronic acid suspensions [37]. The outcome was an incipient regeneration of the medial meniscus and a significant reduction of joint cartilage degeneration, osteophytic remodelling, and subchondral sclerosis during OA. Based on these encouraging results, a multicenter phase I/II trial for the treatment of knee injuries by stem cell injection has been launched [38]. Furthermore, in a case report study, Centeno and colleagues [39] recently reported a significantly increased cartilage and meniscus volume in OA using percutaneously injected MSCs.

Besides stem cell injection, matrix-assisted MSC therapies are of special interest. Here, the regenerative potential of MSCs is combined with the advantages of MACl over ACl. In clinical approaches, Wakitani and colleagues have transplanted collagens combined with autologous human MSCs in human OA knees [40] and in cartilage defects of the patellofemoral joint [41]. Although the transplantation of MSCs resulted in enhanced cartilage tissue formation, these approaches are preliminary and, from a clinical point of view, are far from established $\mathrm{ACl}$ or $\mathrm{MACl}$. For bone repair, in a clinical pilot study, human MSCs were combined with hydroxyapatite ceramic scaffolds and transplanted into large bone defects [42]. No major complications occurred and complete fusion between implant and host bone occurred 5 to 7 months after surgery. Six to seven years of follow-up revealed good implant integration, and no late fractures in the implant zone were observed. Another interesting therapeutic approach for the future regeneration of osteochondral
Figure 2

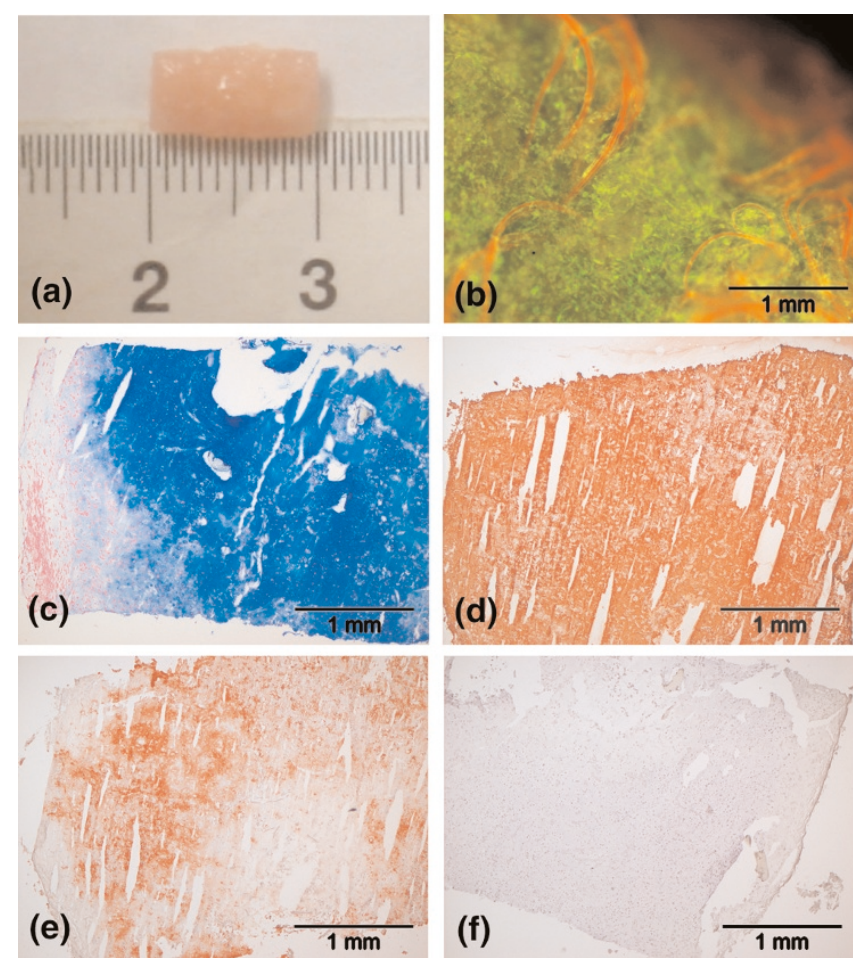

Cartilage tissue engineering with mesenchymal stem cells (MSCs) derived from osteoarthritis (OA) patients. Human MSCs were isolated and expanded from femoral heads of five OA patients undergoing endoprothetic joint replacement. (a) Two and a half million MSCs per $100 \mu \mathrm{L}$ were embedded in fibrinogen PLGA fleeces and chondrogenically induced with transforming growth factor-beta-3. (b) At day 14, propidium iodide/fluorescein diacetate staining revealed a high cell viability (green cells) and homogenous cell distribution. Remaining PLGA fibers appeared red. (c) After 4 weeks, matrix formation was demonstrated by alcian blue staining of cartilage proteoglycans and by antibody staining of (d) collagen type I and (e) cartilage-specific collagen type II. (f) Negative lgG control. In summary, we found no differences between MSCs derived from healthy donors and those from patients with OA. PLGA, poly(DL-lactic acid-co-glycolic acid).

defects relies on biphasic constructs, consisting, for instance, of plugs made of chondrocytes or MSCs embedded in a collagen gel (for cartilage repair), overlying a tricalcium phosphate block (for bone repair) [43].

\section{In situ regeneration: next generation of tissue engineering}

Cell expansion in clean rooms is time-consuming and expensive. Moreover, biopsy is stressful for the patient, cells are not immediately available, and in most cases, ex vivo incubation of transplants is less efficient than in vivo incubation. So, the next generation of tissue engineering focuses on in situ approaches [44]. Here, for joint repair, scaffolds combined with chemotactic molecules and joint tissue formation-stimulating factors are transplanted, resulting in the in situ recruitment of bone marrow MSCs to the defect 
sites of degenerated cartilage and bone and their subsequent use for factor-guided joint repair.

For MSCs, their potential to home to the bone marrow, to migrate, and to engraft into several tissues following systemic infusion has been observed in animal studies (reviewed in [45]). Microfracture or Pridie drilling, each of which is a technique to stimulate cartilage self-repair (reviewed in [1]), is based on the migration of bone marrow MSCs to the injured site and results in the formation of a fibrocartilage repair tissue. Transplantation of a cell-free implant consisting of polyglycolic acid combined with serum as a chemotactic factor and $\mathrm{HA}$ as a chondroinductor in a full-thickness cartilage defect pretreated with microfracture resulted in the migration of ovine MSCs into the implant and in the formation of cartilage-like repair tissue. Controls treated with microfracture showed no formation of repair tissue [46]. Very recently, these results were translated into a clinically applied in situ tissue engineering product [47].

Although MSC migration factors and their mechanisms are not known yet, molecules such as chemokines [48], bone morphogenetic proteins and platelet-derived growth factor [49], and hyaluronan [50] have been shown to have a dosedependent chemotactic effect. In the context of arthritis, it is worth mentioning that synovial fluids from the joint of normal donors and OA patients comparably recruit normal donor MSCs, whereas synovial fluid from RA patients showed significantly reduced migratory activity on these cells [50]. We have identified a chemokine-dependent migratory potential of OA patient-derived MSCs [36].

\section{Mesenchymal stem cells, in vivo immune suppression, arthritis, and tissue engineering}

Identification of immunosuppressive cells, targeting cells that are abnormal in ADs, recently has generated high interest for their clinical use (reviewed in [51]). Here, since they have immunosuppressive and anti-inflammatory characteristics, MSCs are of high interest. The cellular and molecular bases for this effect have been reviewed by others [9,51]. Briefly, the effect is dose-dependent and is exerted on T-cell responses to polyclonal stimuli or their cognate peptide [51]. Inhibition seems not to be antigen-specific and targets primary and secondary T-cell responses. T-cell suppression is not cognate-dependent since it can be observed applying major histocompatibility complex (MHC) class I-negative MSCs and it can be exerted by MSCs of an MHC origin that is different from that of the target $T$ cells. First of all, the immunosuppressive effect of MSCs is directed on the proliferation level as a result of an increased expression of the cell cycle inhibitor p27 and a repressed expression of the cell cycle regulatory gene cyclin D2, and it also affects other immune cells. The mechanisms underlying the immunosuppressive effect are still not clear, but in the context of trophic activity, secreted soluble factors such as interleukin (IL)-10, IDO (indoleamine 2,3-dioxygenase), hepatocyte growth factor, TGF- $\beta$, prostaglandins, and nitric oxide provide an environment that stimulates immunosuppression. Furthermore, cell-cell contacts are of importance. The immunosuppressive activity is not a standard MSC feature. It requires MSCs that are 'licensed' in an appropriate environment [51]. Interferon- $\gamma$ or IL-1 $\beta$ represents an inductor of such an activity, and tumor necrosis factor-alpha (TNF- $\alpha$ ) can reverse this activity of MSCs in vivo.

These characteristics and their tissue formation potential make MSCs appropriate cells for tissue engineering in AD. Here, degenerated joint tissues will be substituted by MSCbased tissue engineering approaches described above, and simultaneously neo-tissue will be protected. Clearly, this is not state of the art but a promising strategy for further research. In regard to tissue protection, Bartholomew and colleagues [52] reported that intravenous injection of MSCs extended the survival of an allogeneic skin graft in baboons. Additionally, Zappia and colleagues [53] demonstrated the therapeutic efficacy of MSCs in the murine model of multiple sclerosis. Here, MSC injection decreased the clinical signs of demyelinization when injected before or at the very early stage of the disease. Injection of allogeneic MSCs has also been suggested as a treatment strategy for collagen-induced arthritis, a mouse model of human RA [54]. In this model, mice were immunized with type II collagen and received a single intraperitoneal injection of allogeneic MSCs. This prevented the outcome of damage to joint cartilage and bone. Moreover, this reduced the proliferation of $\mathrm{T}$ lymphocytes and modulated the expression of inflammatory cytokines. Thus, in vivo models indicated the protective activity and allogeneic use of MSCs for tissue engineering in AD. Moderating these findings about allogeneic use, in a murine model of allogeneic hematopoietic stem cell transplantation (HSCT), coinjection of autologous MSCs has improved the allograft survival, whereas injection of allogeneic MSCs resulted in a significant increase in cell rejection [55]. Moreover, in a mouse model of graft versus host disease (GvHD), injection of allogeneic MSCs had no beneficial effect on the GvHD [56]. Finally, Djouad and colleagues [57] reported that the addition of TNF- $\alpha$ was sufficient to reverse the immunosuppressive effect of MSCs on T-cell proliferation. This indicates that parameters related to inflammation influence the immunosuppressive properties and that tissue engineering applications in AD should be associated with anti-TNF- $\alpha$ therapy.

Human MSCs have been tested in the clinical setting of HSCT, whereby a patient with severe GvHD of the gut and liver showed transiently improved liver values and intestinal function promptly after infusion of allogeneic MSCs from a haplo-identical donor [58]. However, before the use of MSCs for tissue engineering in $A D$, several open questions have to be solved. So far it is not known whether MSCs from patients with different ADs display normal functions. MSCs from RA, systemic lupus erythematosus, and systemic sclerosis patients exhibit features of early senescence $[59,60]$. We 
reported that MSCs from RA patients showed a reduced clonogenic and proliferative activity but were normal in differentiation capacity [60]. However, in patients with systemic sclerosis, the adipogenic and osteogenic potential was impaired [61]. Importantly, MSCs from AD patients have retained their immunosuppressive activity [62]. Therefore, they hopefully can be applied as autologous cells, which has become important following the demonstration in nonmyeloablated mice that allogeneic MSCs are immunogenic and can be rejected [55].

\section{Cell sources for tissue engineering in rheumatic diseases}

Today, autologous chondrocytes represent the only cell type routinely used for joint cartilage repair. In the future, autologous or allogeneic bone marrow MSCs most likely will serve as an additional cell source, for example, for the repair of osteochondral defects. Adult MSCs and progenitor cells from adipose tissue, placenta, amniotic fluid, periosteum, umbilical cord blood and vein, cartilage, bone, skeletal muscle, and synovium have been described and show properties similar to bone marrow MSCs [63]. Therefore, they also represent possible candidates for tissue engineering in rheumatic diseases. However, the vast amount of data describing their proliferation capacity, their joint cartilage and bone regeneration potential, their migratory behavior for in situ approaches, their allogeneic use, and so on is sometimes confusing and, as described for bone marrow MSCs, contradictory. Clearly, a 'gold standard' cell type has not yet been extracted from the in vitro and in vivo data. Besides bone marrow MSCs, cartilage-inherent MSCs or MSCs from joint synovium seem to be very interesting candidates, especially for in situ applications. Cartilage of healthy donors and of patients with OA contains MSCs that can develop into chondrocytes and osteoblasts [64]. In addition, several studies have demonstrated that synovium-derived MSCs of healthy donors and OA patients show a high expansion capacity and a multilineage differentiation potential, display the same phenotype as bone marrow MSCs in terms of surface marker expression, suppress T-cell response, and have a more pronounced chondrogenic capacity than bone marrow MSCs $[9,65]$. However, unlike chondrocytes, in vitro differentiated MSCs from the synovium failed to form ectopic stable cartilage in vivo [66].

Besides MSCs, human ESCs may represent promising candidates for joint repair. In vitro and in vivo studies have demonstrated their osteogenic and chondrogenic potential $[67,68]$. Political, ethical, and practical problems, such as teratoma formation, hamper their clinical use. Very recently, in two independent and pathbreaking studies, human adult skin fibroblasts were induced to pluripotent stem cells (iPSs) with ESC character $[69,70]$. This may pave the way for cell-based joint repair. In detail, the ectopic expression of a selected group of important ESC genes in somatic cells, like normal human skin fibroblasts, enables these cells to exhibit many of the specific characteristics of ESCs. Given the abundance and ease with which autologous skin fibroblasts can be harvested, it seems only a question of time until such an approach will be used to provide patients, including OA and RA patients, with autologous-specific cell types that are needed for tissue regeneration. Clearly, problems in the handling of iPSs, such as the use of viral vectors, teratoma formation, and lack of appropriate differentiation protocols, have to be solved before thinking about clinical applications. Moreover, as for all alternative new cell sources, the open question is whether their possible advantages justify the labor and cost-intensive launch of a new clinical product.

\section{Tissue engineering and advanced three- dimensional models}

Tissue engineering also offers the opportunity to establish complex 3D cell-matrix cultures that mimic the cellular environment and thus to provide an important tool to study tissue development, remodeling, and repair. Although so far they do not reach the quality of native tissues, highly organized 3D in vitro cultures of human cells and ECMs facilitate the establishment of physiological ex vivo models reflecting human significance under well-defined and reproducible conditions. Three-dimensional in vitro models also offer advantages compared with animal models, including low complexity and cost, fewer ethical concerns, easy data processability and reproducibility, and automatization and standardization [12].

The increasing prevalence of cartilage destruction in $\mathrm{OA}$ and RA has entailed an intensified demand for cartilage in vitro models for the analysis of the destructive pathophysiological processes leading to cartilage breakdown in RA and OA. For this purpose, 3D in vitro high-density chondrocyte pellet and alginate cultures help to preserve/regain the chondrocyte phenotype following monolayer expansion by offering cell-cell and cell-matrix interactions [71,72]. Chondrocyte 3D pellet and alginate cultures show similar responses to IL-1 $\beta$ like native cartilage explants, indicating the relevance of both in vitro systems to study chondrocyte biology on proinflammatory stimuli $[10,73]$. For the in vitro analysis of cartilage destruction in RA, interactions between (a) chondrocytes as a single cell type entirely conducting the cartilage remodelling process and (b) synovial fibroblasts as the key player of RArelated cartilage destruction $[74,75]$ are of immense importance. An interactive in vitro coculture model of cartilage pellets and RA synovial fibroblasts (RASFs) that offered direct cell contact between both cell types (Figure 3) showed that RASF aggressively invaded the cartilage and caused erosion of the chondrocyte pellet as described in vivo [76]. Although the attachment of RASF to cartilage is a prominent feature of RA-related cartilage destruction, direct cell contact between chondrocytes and RASF does not necessarily seem to be required for the destructive modulation of the chondrocyte phenotype. Recent studies using an interactive alginate-based in vitro model composed of human 


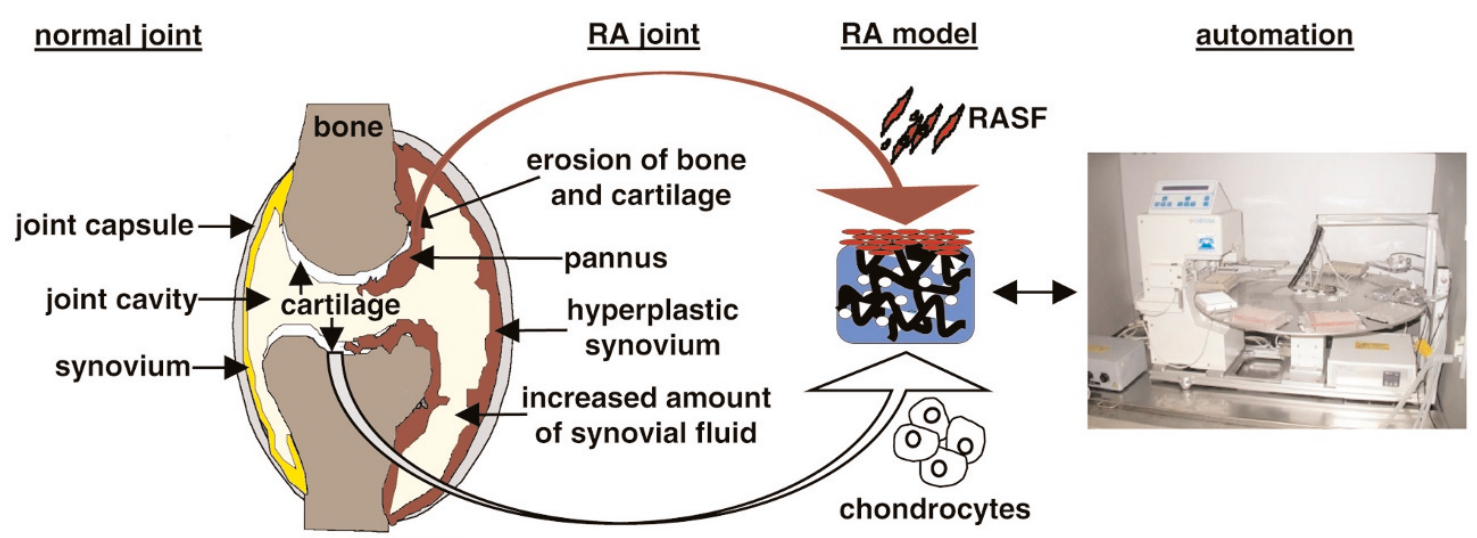

Three-dimensional (3D) in vitro pannus model for rheumatoid arthritis. During rheumatoid arthritis (RA), formation of an invasive pannus tissue in the synovial joints occurs. The pannus tissue ultimately leads to erosion of the underlying cartilage and even bone. Key players in pannus formation are the RA synovial fibroblasts (RASFs), showing an aggressive invasive behavior. For simulation of RA in the 3D in vitro pannus model, human chondrocytes are harvested from healthy donors and cultured for 2 weeks as high-density micromasses in 96-well plates. During this period, cartilage matrix formation occurs. Subsequently, micromasses are coated with human RASFs. After 14 days of coculture allowing intensive interactions of both cell types, the model can be used for the high-throughput screening of antirheumatic drugs. For automation, the CyBi ${ }^{\text {Tw }}$-Disk workstation (CyBio Inc., Jena, Germany) for parallel liquid handling is used.

chondrocytes and conditioned supernatants of RASF showed that soluble mediators released from RASF shift the chondrocyte gene expression toward catabolism and thus led to chondrocyte dysfunction [11]. This study provided comprehensive insight into the molecular mechanisms in chondrocytes that are associated with RA-related cartilage destruction involving marker genes of inflammation/nuclear factor-kappa-B signalling, cytokines/chemokines and receptors, matrix degradation, and suppressed matrix synthesis and thus revealed potential molecular targets of RA-related cartilage destruction. The respective in vitro models may serve as human disease models of RA-related cartilage destruction and may help to elucidate the molecular effects of antirheumatic drugs on human chondrocytes. For this purpose, human chondrocytes were cultured in alginate beads and stimulated with the supernatant of RASF and normal donor synovial fibroblasts and antirheumatic drugtreated RASF (like methotrexate). Microarray analysis and enzyme-linked immunosorbent assay were performed to determine RA-relevant chondrocyte gene expression, antirheumatic drug response signatures, and potential new molecular targets [77].

\section{Conclusions}

At present, tissue engineering is applied mostly for the clinical treatment of traumatic joint cartilage defects and uses autologous chondrocytes or in situ recruited bone marrow MSCs. Beyond that, clinical applications for the treatment of degenerative arthritis (OA), based on chondrocytes or MSCs combined with resorbable transplants (allowing a stable fixation in defects without perifocal solid cartilage shoulder), are on the way. Here, from a clinical point of view, MSC approaches are far from established $\mathrm{ACl}$ or $\mathrm{MACl}$. Prospectively, joint tissue engineering will be of utmost importance if it can be used for patients with advanced rheumatism. Since chronic joint diseases are accompanied by inflammatory conditions in the joint, which presumably will impair tissue formation and degrade tissue-engineered neojoint structures, anti-inflammatory treatment will be of crucial importance. Screening for factors relevant to arthritis can be performed in tissue-engineered 3D models reflecting the human environment. Such factors can be applied separately, can be released from the transplant itself, or can be released by cells. Here, MSCs are of special interest since, besides their plasticity, they show immunosuppressive and antiinflammatory characteristics in vitro and in both preclinical and clinical studies. Thus, they fulfill the two basic requirements for tissue engineering in rheumatic diseases, namely to generate tissue and to protect it. However, it should be clearly stated that, despite more than 15 years of tissue engineering research, such applications are still in a rather early phase. For instance, characteristics of MSCs from patients with different diseases are not well known, and even the question of whether allogeneic or autologous MSC use is preferable is still controversial. Moreover, recently, most of the research community has been focused on bone marrow MSCs. Prospectively, MSCs from other tissue sources or pluripotent stem cells may be additional appropriate cell candidates. For in situ therapies using cell-free biomaterials combined with cell-recruiting factors, synovium-derived MSCs with characteristics similar to bone marrow MSCs represent promising candidates. 


\section{The Scientific Basis of Rheumatology: A Decade of Progress}

This article is part of a special collection of reviews, The Scientific Basis of Rheumatology: A Decade of Progress, published to mark Arthritis Research \& Therapy's 10th anniversary.

Other articles in this series can be found at: http://arthritis-research.com/sbr

\section{Competing interests}

MS works as a consultant for BioTissue Technologies $\mathrm{GmbH}$ (Freiburg, Germany). This company develops autologous tissue transplants for the regeneration of bone and cartilage. $\mathrm{He}$ is also shareholder of CellServe $\mathrm{GmbH}$ (Berlin, Germany) and BioRetis $\mathrm{GmbH}$ (Berlin, Germany). The product activities of both companies have no connection with the topics reviewed here. JR declares that he has no competing interests.

\section{Acknowledgments}

This study was supported by grants from the Investitionsbank Berlin and the European Regional Development Fund (grant number 10128098) and the 6th European Union Framework Program (STEPS consortium, grant number NMP3-CT-2005-500465). The grant sponsors had absolutely no influence on the writing of the manuscript or on the decision to submit the manuscript to Arthritis Research \& Therapy.

\section{References}

1. Simon TM, Jackson DW: Articular cartilage: injury pathways and treatment options. Sports Med Arthrosc 2006, 14:146-154.

2. Steadman JR, Ramappa AJ, Maxwell RB, Briggs KK: An arthroscopic treatment regimen for osteoarthritis of the knee. Arthroscopy 2007, 23:948-955.

3. Hollander AP, Dickinson SC, Sims TJ, Brun P, Cortivo R, Kon E, Marcacci M, Zanasi S, Borrione A, De Luca C, Pavesio A, Soranzo $\mathrm{C}$, Abatangelo G: Maturation of tissue engineered cartilage implanted in injured and osteoarthritic human knees. Tissue Eng 2006, 12:1787-1798.

4. Ossendorf C, Kaps C, Kreuz PC, Burmester GR, Sittinger M, Erggelet C: Treatment of posttraumatic and focal osteoarthritic cartilage defects of the knee with autologous polymer-based three-dimensional chondrocyte grafts: 2-year clinical results. Arthritis Res Ther 2007, 9:R41.

5. Pittenger MF, Mackay AM, Beck SC, Jaiswal RK, Douglas R, Mosca JD, Moorman MA, Simonetti DW, Craig S, Marshak DR: Multilineage potential of adult human mesenchymal stem cells. Science 1999, 284:143-147.

6. Johnstone B, Hering TM, Caplan Al, Goldberg VM, Yoo JU: In vitro chondrogenesis of bone marrow-derived mesenchymal progenitor cells. Exp Cell Res 1998, 238:265-272.

7. Jaiswal N, Haynesworth SE, Caplan Al, Bruder SP: Osteogenic differentiation of purified, culture-expanded human mesenchymal stem cells in vitro. J Cell Biochem 1997, 64:295312.

8. Caplan Al, Dennis JE: Mesenchymal stem cells as trophic mediators. J Cell Biochem 2006, 98:1076-1084.

9. Jorgensen C, Djouad F, Bouffi C, Mrugala D, Noël D: Multipotent mesenchymal stromal cells in articular diseases. Best Pract Res Clin Rheumatol 2008, 22:269-284.
10. Fedewa MM, Oegema TR Jr., Schwartz MH, MacLeod A, Lewis $\mathrm{JL}$ : Chondrocytes in culture produce a mechanically functional tissue. J Orthop Res 1998, 16:227-236.

11. Andreas K, Lübke C, Häupl T, Dehne T, Morawietz L, Ringe J, Kaps C, Sittinger M: Key regulatory molecules of cartilage destruction in rheumatoid arthritis: an in vitro study. Arthritis Res Ther 2008, 10:R9.

12. Ibold Y, Frauenschuh S, Kaps C, Sittinger M, Ringe J, Goetz PM: Development of a high-throughput screening assay based on the 3-dimensional pannus model for rheumatoid arthritis. J Biomol Screen 2007, 12:956-965.

13. Brittberg $M$, Lindahl A, Nilsson $A$, Ohlsson $C$, Isaksson $O$, Peterson L: Treatment of deep cartilage defects in the knee with autologous chondrocyte transplantation. N Engl J Med 1994, 331:889-895.

14. Micheli LJ, Browne JE, Erggelet C, Fu F, Mandelbaum B, Moseley $\mathrm{JB}$, Zurakowski D: Autologous chondrocyte implantation of the knee: multicenter experience and minimum 3-year follow-up. Clin J Sport Med 2001, 11:223-228.

15. Peterson L, Minas T, Brittberg M, Nilsson A, Sjogren-Jansson E, Lindahl A: Two- to 9-year outcome after autologous chondrocyte transplantation of the knee. Clin Orthop Relat Res 2000, 374:212-234

16. Roberts S, McCall IW, Darby AJ, Menage J, Evans H, Harrison PE, Richardson JB: Autologous chondrocyte implantation for cartilage repair: monitoring its success by magnetic resonance imaging and histology. Arthritis Res Ther 2003, 5:R60-73.

17. Steinwachs M, Kreuz PC: Autologous chondrocyte implantation in chondral defects of the knee with a type I/III collagen membrane: a prospective study with a 3-year follow-up. Arthroscopy 2007, 23:381-387.

18. Knutsen G, Drogset JO, Engebretsen L, Grontvedt T, Isaksen V, Ludvigsen TC, Roberts S, Solheim E, Strand T, Johansen O: A randomized trial comparing autologous chondrocyte implantation with microfracture. Findings at five years. J Bone Joint Surg Am 2007, 89:2105-2112

19. Saris DB, Vanlauwe J, Victor J, Haspl M, Bohnsack M, Fortems $Y$, Vandekerckhove B, Almqvist KF, Claes T, Handelberg F, Lagae K, van der Bauwhede J, Vandenneucker $H$, Yang KG, Jelic $M$, Verdonk R, Veulemans N, Bellemans J, Luyten FP: Characterized chondrocyte implantation results in better structural repair when treating symptomatic cartilage defects of the knee in a randomized controlled trial versus microfracture. Am J Sports Med 2008, 36:235-246.

20. Behrens $P$, Bitter T, Kurz B, Russlies M: Matrix-associated autologous chondrocyte transplantation/implantation (MACT/ MACI)- 5-year follow-up. Knee 2006, 13:194-202.

21. Marcacci M, Berruto M, Brocchetta D, Delcogliano A, Ghinelli D, Gobbi A, Kon E, Pederzini L, Rosa D, Sacchetti GL, Stefani G, Zanasi S: Articular cartilage engineering with Hyalograft C: 3year clinical results. Clin Orthop Relat Res 2005, (435):96-105.

22. Erggelet $C$, Sittinger M, Lahm A: The arthroscopic implantation of autologous chondrocytes for the treatment of full-thickness cartilage defects of the knee joint. Arthroscopy 2003, 19: 108-110.

23. Drobnic M, Radosavljevic D, Ravnik D, Pavlovcic V, Hribernik M: Comparison of four techniques for the fixation of a collagen scaffold in the human cadaveric knee. Osteoarthritis Cartilage 2006, 14:337-344.

24. Bartlett W, Skinner JA, Gooding CR, Carrington RW, Flanagan AM, Briggs TW, Bentley G: Autologous chondrocyte implantation versus matrix-induced autologous chondrocyte implantation for osteochondral defects of the knee: a prospective, randomised study. J Bone Joint Surg Br 2005, 87:640-645.

25. von der Mark K, Kirsch T, Nerlich A, Kuss A, Weseloh G, Gluckert $\mathrm{K}$, Stoss $\mathrm{H}$ : Type $\mathrm{X}$ collagen synthesis in human osteoarthritic cartilage. Indication of chondrocyte hypertrophy. Arthritis Rheum 1992, 35:806-811.

26. Aigner T, Bertling W, Stoss H, Weseloh G, von der Mark K: Independent expression of fibril-forming collagens I, II, and III in chondrocytes of human osteoarthritic cartilage. J Clin Invest 1993, 91:829-837.

27. Dehne T, Karlsson C, Ringe J, Lindahl A, Sittinger M: Gene expression profiling of HYAFF-11 cartilage transplants generated by chondrocytes from OA donors [abstract]. Tissue Eng Part $A$ 2008, 14:737.

28. Stevens MM, George $\mathrm{JH}$ : Exploring and engineering the cell 
surface interface. Science 2005, 310:1135-1138.

29. Teo WE, He W, Ramakrishna S: Electrospun scaffold tailored for tissue-specific extracellular matrix. Biotechnol J 2006, 1: 918-929.

30. Sohier J, Moroni L, van Blitterswijk C, de Groot K, Bezemer JM: Critical factors in the design of growth factor releasing scaffolds for cartilage tissue engineering. Expert Opin Drug Deliv 2008, 5:543-566.

31. Caplan Al: Mesenchymal stem cells. J Orthop Res 1991, 9:641650.

32. Kuo CK, Li WJ, Mauck RL, Tuan RS: Cartilage tissue engineering: its potential and uses. Curr Opin Rheumatol 2006, 18:6473.

33. Murphy JM, Dixon K, Beck S, Fabian D, Feldman A, Barry F: Reduced chondrogenic and adipogenic activity of mesenchymal stem cells from patients with advanced osteoarthritis. Arthritis Rheum 2002, 46:704-713.

34. Scharstuhl A, Schewe B, Benz K, Gaissmaier C, Buhring HJ, Stoop R: Chondrogenic potential of human adult mesenchymal stem cells is independent of age or osteoarthritis etiology. Stem Cells 2007, 25:3244-3251.

35. Kafienah W, Mistry S, Dickinson SC, Sims TJ, Learmonth I, Hollander AP: Three-dimensional cartilage tissue engineering using adult stem cells from osteoarthritis patients. Arthritis Rheum 2007, 56:177-187.

36. Eder J, Dehne T, Perka C, Ringe J, Sittinger M: Towards in situ tissue repair of osteoarthritis: differentiation and migration potential of patient-derived mesenchymal stem cells [abstract]. Tissue Eng Part A 2008, 14:923.

37. Murphy JM, Fink DJ, Hunziker EB, Barry FP: Stem cell therapy in a caprine model of osteoarthritis. Arthritis Rheum 2003, 48: 3464-3474.

38. Osiris Therapeutics, Inc. homepage [http://www.osiristx.com].

39. Centeno CJ, Busse D, Kisiday J, Keohan C, Freeman M, Karli D: Increased knee cartilage volume in degenerative joint disease using percutaneously implanted, autologous mesenchymal stem cells. Pain Physician 2008, 11:343-353.

40. Wakitani S, Imoto K, Yamamoto T, Saito M, Murata N, Yoneda M: Human autologous culture expanded bone marrow mesenchymal cell transplantation for repair of cartilage defects in osteoarthritic knees. Osteoarthritis Cartilage 2002, 10:199-206.

41. Wakitani S, Nawata M, Tensho K, Okabe T, Machida H, Ohgushi $\mathrm{H}$ : Repair of articular cartilage defects in the patello-femoral joint with autologous bone marrow mesenchymal cell transplantation: three case reports involving nine defects in five knees. J Tissue Eng Regen Med 2007, 1:74-79.

42. Marcacci M, Kon E, Moukhachev V, Lavroukov A, Kutepov S, Quarto R, Mastrogiacomo M, Cancedda R: Stem cells associated with macroporous bioceramics for long bone repair: 6to 7-year outcome of a pilot clinical study. Tissue Eng 2007, 13:947-955.

43. Tanaka T, Komaki H, Chazono M, Fujii K: Use of a biphasic graft constructed with chondrocytes overlying a beta-tricalcium phosphate block in the treatment of rabbit osteochondral defects. Tissue Eng 2005, 11:331-339.

44. Ringe J, Häupl T, Sittinger M: Future of tissue engineering in rheumatic diseases. Expert Opin Biol Ther 2007, 7:283-287.

45. Chamberlain G, Fox J, Ashton B, Middleton J: Concise review: mesenchymal stem cells: their phenotype, differentiation capacity, immunological features, and potential for homing. Stem Cells 2007, 25:2739-2749.

46. Erggelet $\mathrm{C}$, Neumann K, Endres M, Haberstroh K, Sittinger M, Kaps C: Regeneration of ovine articular cartilage defects by cell-free polymer-based implants. Biomaterials 2007, 28:55705580.

47. BioTissue Technologies GmbH homepage [http://www.biotissue.de].

48. Ringe J, Strassburg S, Neumann $K$, Endres $M$, Notter $M$, Burmester GR, Kaps C, Sittinger M: Towards in situ tissue repair: human mesenchymal stem cells express chemokine receptors CXCR1, CXCR2 and CCR2, and migrate upon stimulation with CXCL8 but not CCL2. J Cell Biochem 2007, 101: 135-146.

49. Fiedler J, Roderer G, Gunther KP, Brenner RE: BMP-2, BMP-4, and PDGF-bb stimulate chemotactic migration of primary human mesenchymal progenitor cells. J Cell Biochem 2002, 87:305-312.
50. Endres M, Neumann K, Häupl T, Erggelet C, Ringe J, Sittinger M, Kaps C: Synovial fluid recruits human mesenchymal progenitors from subchondral spongious bone marrow. J Orthop Res 2007, 25:1299-1307.

51. Dazzi F, van Laar JM, Cope A, Tyndall A: Cell therapy for autoimmune diseases. Arthritis Res Ther 2007, 9:206.

52. Bartholomew A, Sturgeon C, Siatskas M, Ferrer K, Mclntosh K, Patil S, Hardy W, Devine S, Ucker D, Deans R, Moseley A, Hoffman R: Mesenchymal stem cells suppress lymphocyte proliferation in vitro and prolong skin graft survival in vivo. Exp Hematol 2002, 30:42-48.

53. Zappia E, Casazza S, Pedemonte E, Benvenuto F, Bonanni I, Gerdoni E, Giunti D, Ceravolo A, Cazzanti F, Frassoni F, Mancardi G, Uccelli A: Mesenchymal stem cells ameliorate experimental autoimmune encephalomyelitis inducing T-cell anergy. Blood 2005, 106:1755-1761.

54. Augello A, Tasso R, Negrini SM, Cancedda R, Pennesi G: Cell therapy using allogeneic bone marrow mesenchymal stem cells prevents tissue damage in collagen-induced arthritis. Arthritis Rheum 2007, 56:1175-1186.

55. Nauta AJ, Westerhuis G, Kruisselbrink AB, Lurvink EG, Willemze $\mathrm{R}$, Fibbe WE: Donor-derived mesenchymal stem cells are immunogenic in an allogeneic host and stimulate donor graft rejection in a nonmyeloablative setting. Blood 2006, 108: 2114-2120.

56. Sudres M, Norol F, Trenado A, Grégoire S, Charlotte F, Levacher B, Lataillade JJ, Bourin P, Holy X, Vernant JP, Klatzmann D, Cohen JL: Bone marrow mesenchymal stem cells suppress lymphocyte proliferation in vitro but fail to prevent graft-versus-host disease in mice. J Immunol 2006, 176:7761-7767.

57. Djouad F, Fritz V, Apparailly F, Louis-Plence P, Bony C, Sany J, Jorgensen C, Noel D: Reversal of the immunosuppressive properties of mesenchymal stem cells by tumor necrosis factor alpha in collagen-induced arthritis. Arthritis Rheum 2005, 52:1595-1603.

58. Le Blanc K, Frassoni $F$, Ball L, Locatelli F, Roelofs $H$, Lewis I, Lanino E, Sundberg B, Bernardo ME, Remberger M, Dini G, Egeler RM, Bacigalupo A, Fibbe W, Ringdén O; Developmental Committee of the European Group for Blood and Marrow Transplantation: Mesenchymal stem cells for treatment of steroidresistant, severe, acute graft-versus-host disease: a phase II study. Lancet 2008, 371:1579-1586.

59. Papadaki HA, Marsh JC, Eliopoulos GD: Bone marrow stem cells and stromal cells in autoimmune cytopenias. Leuk Lymphoma 2002, 43:753-760.

60. Kastrinaki MC, Sidiropoulos $P$, Roche S, Ringe J, Lehmann S, Kritikos $\mathrm{H}$, Vlahava VM, Delorme B, Eliopoulos GD, Jorgensen C, Charbord P, Häupl T, Boumpas DT, Papadaki HA: Functional, molecular and proteomic characterisation of bone marrow mesenchymal stem cells in rheumatoid arthritis. Ann Rheum Dis 2008, 67:741-749.

61. Del Papa N, Quirici N, Soligo D, Scavullo C, Cortiana M, Borsotti C, Maglione W, Comina DP, Vitali C, Fraticelli P, Gabrielli A, Cortelezzi A, Lambertenghi-Deliliers G: Bone marrow endothelial progenitors are defective in systemic sclerosis. Arthritis Rheum 2006, 54:2605-2615.

62. Bocelli-Tyndall C, Bracci L, Spagnoli G, Braccini A, Bouchenaki M, Ceredig R, Pistoia V, Martin I, Tyndall A: Bone marrow mesenchymal stromal cells (BM-MSCs) from healthy donors and auto-immune disease patients reduce the proliferation of autologous- and allogeneic-stimulated lymphocytes in vitro. Rheumatology (Oxford) 2007, 46:403-408.

63. Kwan MD, Slater BJ, Wan DC, Longaker MT: Cell-based therapies for skeletal regenerative medicine. Hum Mol Genet 2008, 17:R93-98.

64. Fickert S, Fiedler J, Brenner RE: Identification of subpopulations with characteristics of mesenchymal progenitor cells from human osteoarthritic cartilage using triple staining for cell surface markers. Arthritis Res Ther 2004, 6:R422-432.

65. Pei M, He F, Vunjak-Novakovic G: Synovium-derived stem cellbased chondrogenesis. Differentiation 2008, 76:1044-1056.

66. De Bari C, Dell'Accio F, Luyten FP: Failure of in vitro-differentiated mesenchymal stem cells from the synovial membrane to form ectopic stable cartilage in vivo. Arthritis Rheum 2004, 50: 142-150.

67. Bielby RC, Boccaccini AR, Polak JM, Buttery LD: In vitro differentiation and in vivo mineralization of osteogenic cells derived 
from human embryonic stem cells. Tissue Eng 2004, 10:15181525.

68. Wakitani S, Aoki H, Harada $\mathrm{Y}$, Sonobe M, Morita $\mathrm{Y}, \mathrm{Mu} \mathrm{Y}$, Tomita N, Nakamura Y, Takeda S, Watanabe TK, Tanigami A: Embryonic stem cells form articular cartilage, not teratomas, in osteochondral defects of rat joints. Cell Transplant 2004, 13:331336.

69. Takahashi K, Tanabe K, Ohnuki M, Narita M, Ichisaka T, Tomoda $\mathrm{K}$, Yamanaka S: Induction of pluripotent stem cells from adult human fibroblasts by defined factors. Cell 2007, 131:861-872.

70. Yu J, Vodyanik MA, Smuga-Otto K, Antosiewicz-Bourget J, Frane JL, Tian S, Nie J, Jonsdottir GA, Ruotti V, Stewart R, Slukvin II, Thomson JA: Induced pluripotent stem cell lines derived from human somatic cells. Science 2007, 318:1917-1920.

71. Zhang Z, McCaffery JM, Spencer RG, Francomano CA: Hyaline cartilage engineered by chondrocytes in pellet culture: histological, immunohistochemical and ultrastructural analysis in comparison with cartilage explants. J Anat 2004, 205:229-237.

72. Bonaventure J, Kadhom N, Cohen-Solal L, Ng KH, Bourguignon J, Lasselin C, Freisinger P: Reexpression of cartilage-specific genes by dedifferentiated human articular chondrocytes cultured in alginate beads. Exp Cell Res 1994, 212:97-104

73. Lemare F, Steimberg N, Le Griel C, Demignot S, Adolphe M: Dedifferentiated chondrocytes cultured in alginate beads: restoration of the differentiated phenotype and of the metabolic responses to interleukin-1beta. J Cell Physiol 1998, 176:303-313.

74. Häupl T, Yahyawi M, Lübke C, Ringe J, Rohrlach T, Burmester GR, Sittinger M, Kaps C: Gene expression profiling of rheumatoid arthritis synovial cells treated with antirheumatic drugs. $J$ Biomol Screen 2007, 12:328-340.

75. Huber LC, Distler O, Tarner I, Gay RE, Gay S, Pap T: Synovial fibroblasts: key players in rheumatoid arthritis. Rheumatology (Oxford) 2006, 45:669-675.

76. Lübke C, Ringe J, Krenn V, Fernahl G, Pelz S, Kreusch-Brinker R, Sittinger $M$, Paulitschke $M$ : Growth characterization of neo porcine cartilage pellets and their use in an interactive culture model. Osteoarthritis Cartilage 2005, 13:478-487.

77. Lübke C, Andreas K, Yahyawi M, Krenn V, Morawietz L, Ringe J, Burmester GR, Häupl T, Kaps C, Sittinger M: Gene expression profiling of an in vitro tissue model for cartilage destruction. Altex 2006, 23:113. 